\title{
Mutations in the Gabrb1 gene promote alcohol consumption through increased tonic inhibition
}

\author{
Quentin M. Anstee $1,2,3, \star$, Susanne Knapp ${ }^{2,3, \star}$, Edward P. Maguire ${ }^{4}$, Alastair M. Hosie . $^{5, \ddagger}$, Philip Thomas ${ }^{5}$, \\ Martin Mortensen ${ }^{5}$, Rohan Bhome ${ }^{5}$, Alonso Martinez ${ }^{3, \dagger}$, Sophie E. Walker ${ }^{6}$, Claire I. Dixon ${ }^{6}$, Kush Ruparelia ${ }^{7}$, \\ Sara Montagnese ${ }^{7} \dagger$, Yu-Ting Kuo ${ }^{8} \dagger$, Amy Herlihy ${ }^{8}$, Jimmy D. Bell ${ }^{8}$, lain Robinson ${ }^{9}$, Irene Guerrini ${ }^{10}$, \\ Andrew McQuillin ${ }^{10}$, Elizabeth M.C. Fisher ${ }^{11}$, Mark A. Ungless ${ }^{8}$, Hugh M.D. Gurling ${ }^{10}$, Marsha Y. Morgan ${ }^{7}$, \\ Steve D.M. Brown ${ }^{2}$, David N. Stephens ${ }^{6}$, Delia Belelli ${ }^{4}$, Jeremy J. Lambert ${ }^{4}$, Trevor G. Smart ${ }^{5}$ \& \\ Howard C. Thomas 2,3
}

\begin{abstract}
Alcohol dependence is a common, complex and debilitating disorder with genetic and environmental influences. Here we show that alcohol consumption increases following

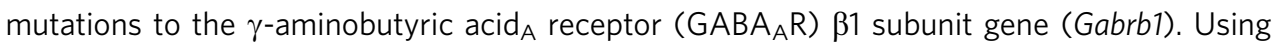
$\mathrm{N}$-ethyl- $\mathrm{N}$-nitrosourea mutagenesis on an alcohol-averse background (F1 BALB/CAnN $\times \mathrm{C} 3 \mathrm{H}$ / $\mathrm{HeH}$ ), we develop a mouse model exhibiting strong heritable preference for ethanol resulting from a dominant mutation (L285R) in Gabrb1. The mutation causes spontaneous GABA ion channel opening and increases GABA sensitivity of recombinant $G A B A_{A} R s$, coupled to increased tonic currents in the nucleus accumbens, a region long-associated with alcohol reward. Mutant mice work harder to obtain ethanol, and are more sensitive to alcohol intoxication. Another spontaneous mutation (P228H) in Gabrb1 also causes high ethanol consumption accompanied by spontaneous GABA ion channel opening and increased accumbal tonic current. Our results provide a new and important link between $G_{A B A_{A} R}$ function and increased alcohol consumption that could underlie some forms of alcohol abuse.
\end{abstract}

\footnotetext{
${ }^{1}$ Institute of Cellular Medicine, The Medical School, Newcastle University, 4th Floor William Leech Building, Framlington Place, Newcastle Upon Tyne NE2 $4 \mathrm{HH}$, UK. ${ }^{2}$ Mammalian Genetics Unit, MRC Harwell, Oxford OX11 ORD, UK. ${ }^{3}$ Department of Gastroenterology and Hepatology, Imperial College, St Mary's Hospital Campus, Praed Street, London W2 1NY, UK. ${ }^{4}$ Division of Neuroscience, Medical Research Institute, University of Dundee, Ninewells Hospital, Dundee DD1 9SY, UK. ${ }^{5}$ Department of Neuroscience, Physiology and Pharmacology, University College London, Gower Street, London WC1E 6BT, UK. ${ }^{6}$ School of Psychology, University of Sussex, Falmer, Brighton, BN1 9QG, UK. ${ }^{7}$ UCL Institute for Liver and Digestive Health, Royal Free Campus, University College London Medical School, London NW3 2PF, UK. ${ }^{8}$ MRC Clinical Sciences Centre, Imperial College London, Hammersmith Hospital, Du Cane Road, London W12 ONN, UK. ${ }^{9}$ Division of Molecular Neuroendocrinology, National Institute for Medical Research, The Ridgeway, Mill Hill, London NW7 1AA, UK. ${ }_{10}$ Molecular Psychiatry Laboratory, Department of Mental Health Sciences, Royal Free and University College London Medical School, Windeyer Institute of Medical Sciences, 46 Cleveland Street, London W1T 4JF, UK. ${ }^{11}$ Department of Neurodegenerative Disease, Institute of Neurology, University College London, Queen Square, London, WC1N 3BG, UK. * These authors contributed equally to this work. † Present addresses: Cancer Genetic Group, Infection and Cancer, Department Microbiology and Parasitology, School of Medicine, University of Antioquia, Medellin, Colombia (A.M.); Department of Medical Imaging, Chi Mei Medical Center, Tainan City, Taiwan (Y.-T.K.); Department of Medicine, via Giustiniani, 2, 35128 Padova, Italy (S.M.). $\ddagger$ Deceased. Correspondence and requests for materials should be addressed to Q.M.A. (email: quentin.anstee@ncl.ac.uk).
} 
O ur understanding of the genetic and molecular basis of alcohol dependence is incomplete. Alcohol abuse has long been associated with facilitation of neurotransmission mediated by the brain's major inhibitory transmitter, GABA, acting via $\mathrm{GABA}_{\mathrm{A}}$ receptors $\left(\mathrm{GABA}_{\mathrm{A}} \mathrm{Rs}\right)$. Recently, a locus within human chromosome 4, containing $\mathrm{GABA}_{\mathrm{A}} \mathrm{R}$ subunit genes encoding $\alpha 2, \alpha 4, \beta 1$ and $\gamma 1$ subunits has been associated with alcohol dependence in humans ${ }^{1-7}$. In particular, haplotypic variations in the GABRA2 gene encoding the $\alpha 2$ subunit have been repeatedly linked with alcohol dependence ${ }^{2,8-10}$. However, the neurobiological basis by which genetic variation translates into alcohol abuse is largely unknown.

Ionotropic $\mathrm{GABA}_{\mathrm{A}} \mathrm{Rs}$ are pentameric ligand-gated ion channels, drawn from a family of 19 proteins, which underpins the expression of $\sim 20-30$ neuronal $\mathrm{GABA}_{\mathrm{A}} \mathrm{R}$ isoforms ${ }^{11}$. These receptors have distinct physiological and pharmacological properties, are heterogeneously expressed in the mammalian CNS and as a consequence can differentially influence behavioural phenotypes ${ }^{12,13}$. Synaptic $\mathrm{GABA}_{\mathrm{A}}$ Rs mediate phasic inhibition, whereas extrasynaptic $\mathrm{GABA}_{\mathrm{A}} \mathrm{Rs}$ are activated by ambient concentrations of GABA and mediate a tonic form of inhibition. Recent evidence has suggested roles for both forms of GABAergic transmission in the neurobiology of addiction ${ }^{14-17}$.

With regard to ethanol, both consumption and preference are reduced following disruption of GABA-mediated tonic inhibition in $\delta$ subunit knock-out $\left(\delta^{-/-}\right)$mice ${ }^{18}$ and a similar impact on ethanol drinking was achieved by RNAi-induced suppression of either $\alpha 4$ (a subunit partner of the $\delta$ subunit) or $\delta$ subunit expression in the rodent nucleus accumbens (NAc) ${ }^{17,18}$. The reduced ethanol self-administration appeared to be a consequence of the altered reinforcing properties of the $\operatorname{drug}^{17,18}$. These actions on ethanol drinking and selfadministration appear to be specific to the activity of $\alpha 4 \beta \delta$ receptors and not a general effect on manipulating GABAergic activity in the NAc, as no differences in ethanol selfadministration have been found in $\alpha 2^{-1-}$ or $\alpha 5^{-1-}$ mice ${ }^{19,20}$, when compared with wild-type (WT) counterparts.

It has been suggested that ethanol may exert a direct action on $\delta$-GABA $A_{A}$ Rs to enhance their function, which might account for the rodent self-administration data. However, whether ethanol exerts such direct effects is controversial ${ }^{21-24}$. An alternative interpretation of the behavioural data posits that the activity of NAc extrasynaptic GABA $_{\mathrm{A}}$ Rs influences the activity of neural circuits underlying certain addictive behaviours such as the desire for alcohol. We were able to explore this possibility by exploiting the availability of two novel mutant mouse lines in which single point mutations in $\mathrm{GABA}_{\mathrm{A}} \mathrm{R} \beta 1$ subunits have occurred. The first line was identified through a phenotype-driven $\mathrm{N}$-ethyl- $\mathrm{N}$ nitrosourea (ENU) mutagenesis screen ${ }^{25,26}$ for alcoholpreferring mice, whereas the second was a spontaneous mutation identified using a genotype-driven approach ${ }^{27}$. Both mutant mouse lines display increased alcohol consumption and self-administration, and are characterized by GABA channels that can open spontaneously, promoting an increased tonic inhibition in NAc medium spiny neurons (MSNs). These findings strongly suggest that the large tonic conductance of MSNs contributes to the increased preference and intake of ethanol by Gabrb1 $+/ L 285 R$ and Gabrb1 ${ }^{+7 P 228 H}$ mice. These data reveal a novel link between $\mathrm{GABA}_{\mathrm{A}} \mathrm{R}$ function and increased alcohol consumption that could lead to a better understanding of some forms of alcohol abuse.

\section{Results}

Alcohol-preferring mouse strains. We identified two dominant mutations in Gabrb1 that induced a phenotypic switch from alcohol aversion to a sustained, strongly heritable alcohol preference. One mutation was generated through phenotypedriven random ENU mutagenesis ${ }^{25,26}\left(G a b r b 1^{L 285 R}\right)$, whereas the other was a spontaneous mutation $\left(G a b r b 1^{P 228 H}\right)$ identified through gene-driven screening of a DNA/sperm archive ${ }^{27}$. Both lines showed highly penetrant ethanol preference throughout over eight and five backcross generations, respectively.

An ENU-induced Gabrb1 mutation confers alcohol preference: Alcohol-averse male BALB/cAnN mice were exposed to $\mathrm{ENU}^{25}$ and crossed to WT $\mathrm{C} 3 \mathrm{H} / \mathrm{HeH}$ females. G1 progeny $(n=1,047)$ were screened in a two-bottle choice test for preference for $10 \%$ $(v / v)$ ethanol with mice showing ethanol preference backcrossed to $\mathrm{C} 3 \mathrm{H} / \mathrm{HeH}$ to test heritability. The ENU-induced mutation was localized to a region on mouse chromosome $5(71.45-73.05 \mathrm{Mb})$, syntenic with a region on human chromosome 4, containing 11 genes including Gabra4 and Gabrb1 (Supplementary Fig. S1). Sequencing identified just one mutation in the $\beta 1$ subunit (Gabrb1 exon 8), a leucine-to-arginine exchange (L285R) in the highly conserved third transmembrane domain (M3), near the M2-M3 linker (Supplementary Fig. S2A), an important area for GABA receptor activation and ion channel gating. The mutation was absent in both parental strains.

A spontaneous Gabrb1 mutation confers alcohol preference: To determine whether other Gabrb1 mutations modified alcohol drinking, we screened a DNA library containing $\sim 10,000$ unique samples from ENU mutagenized male mice (F1 C57BL/6JxC3H/ $\mathrm{HeH}$ ) and identified one sample carrying a non-synonymous proline-to-histidine mutation $(\mathrm{P} 228 \mathrm{H})$ within $\mathrm{M} 1$ of the $\beta 1$ subunit. This proline is highly conserved in $\mathrm{GABA}_{\mathrm{A}} \mathrm{Rs}$ from various species (Supplementary Fig. S2B). While absent in both background strains, the mutation occurred in the non-ENU mutagenized $\mathrm{C} 3 \mathrm{H}$ DNA strand and therefore had arisen spontaneously. Significantly, as with $G a b r b 1^{+/ L 285 R}$ above, Gabrb1 $1^{+/ P 228 H}$ mutants displayed a heritable ethanol preference (Supplementary Fig. S3).

Gabrb1 $1^{+/ L 285 R}$ mutant mice were significantly smaller than WT $(P<0.0001$; Supplementary Fig. S4). A similar but less pronounced size difference was also observed in Gabrb1 $1^{+/ P 228 H}$ mutant mice. Both mutant lines exhibited complete female infertility characterized by underdeveloped corpus luteii. Consequently, we could only study heterozygotes $\left(G a b r b 1^{+/ L 285 R}\right.$ and Gabrb1 $1^{+/ P 228 H}$ ) and their corresponding WT mice. Reduced body size and impaired fertility most likely reflect hypothalamicpituitary axis endocrine deficiency and so analysis of anterior pituitary hormone content was performed. This demonstrated that carriage of either mutant Gabrb1 allele $\left(G a b r b 1^{L 285 R}\right.$ or Gabrb1 ${ }^{P 228 H}$ ) was associated with significant hypothalamicpituitary axis dysfunction (Supplementary Tables S1 and S2). Mutant mice displayed a significant preference for ethanol $\left(G a b r b 1^{+/ L 285 R}\right.$ : Fig. 1a,b; Gabrb1 ${ }^{+/ P 228 H}$ : Supplementary Fig. S3), but not for similarly presented sucrose, saccharin or quinine solutions, suggesting taste or calorific requirements were not driving alcohol preference (Supplementary Table S3). Furthermore, all mice consumed similar daily fluid volumes, despite Gabrb1 ${ }^{+/ L 285 R}$ and, to a lesser extent, Gabrb1 $1^{+/ P 228 H}$ mutant mice possessing lower body weights (Supplementary Fig. S4). The co-segregation of both alcohol preference and body weight traits were observed throughout all eight (for Gabrb1 ${ }^{+}$) $\left.\mathrm{L}^{285 R}\right)$ and five $\left(\mathrm{Gabrb1} 1^{+/ P 228 H}\right)$ generations studied, being present in $123 / 130$ (93\%) of Gabrb1 $1^{+/ L 285 R}$ mice, effectively excluding the possibility of separate mutations causing these components.

Gabrb1 $1^{\text {L285R }}$ and alcohol-seeking behaviour. The motivation for $G a b r b 1^{+/ L 285 R}$ mice to obtain alcohol was assessed using operant self-administration of fluid coupled with a sucrose-fading 
a

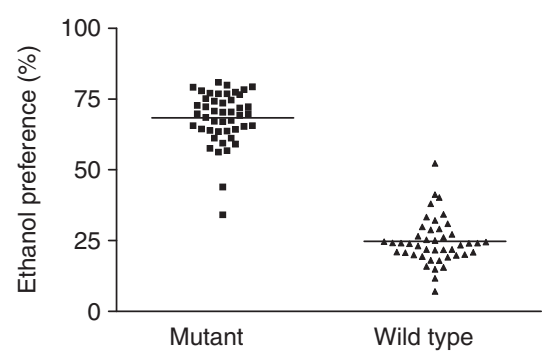

C

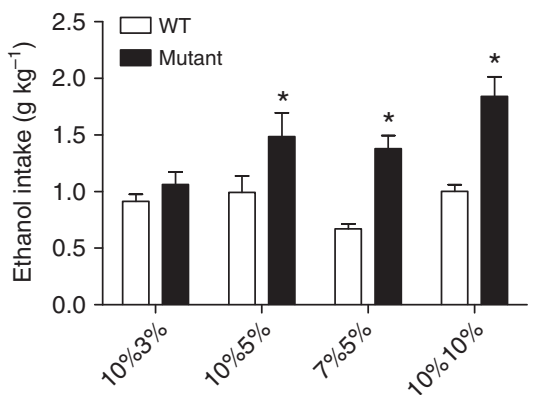

Concentration (sucrose/ethanol \%) b

Daily ethanol consumption

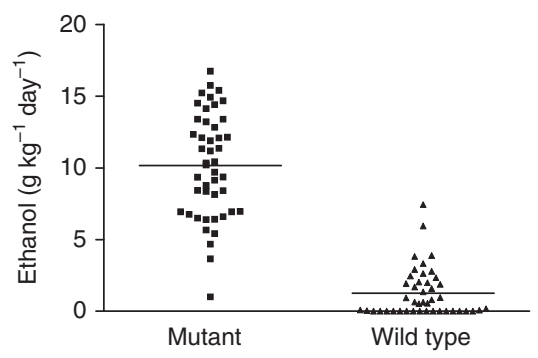

d

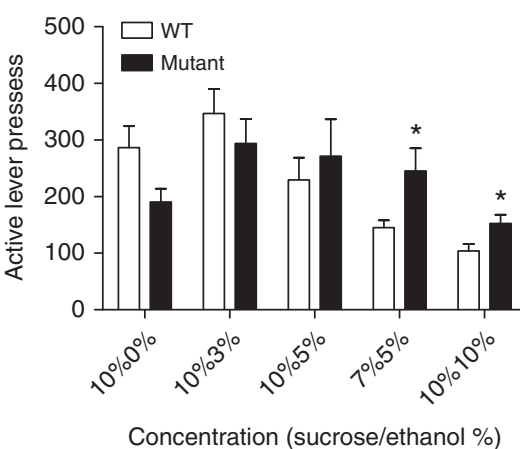

Figure 1 | Alcohol consumption and behavioural phenotype of Gabrb1 $+/ \mathbf{L 2 8 5}$. (a) Ethanol $(10 \% \mathrm{v} / \mathrm{v})$ preference of male Gabrb1 $+/ \mathrm{L} 285(\mathrm{mean}=68.37 \%$, $95 \% \mathrm{Cl}: 65.61-71.13, n=46)$ and WT littermates $(24.67 \%, 22.20-27.13, n=44 ;$-test $P<0.0001)$. (b) Daily ethanol consumption ( $g$ per kg body weight): male Gabrb1 +/L285 $(10.16,95 \% \mathrm{Cl}$ : 9.08-11.25, $n=46)$; WT littermates $(1.24,0.71-1.75 ; t$-test $P<0.0001, n=44)$. (c) Amounts of ethanol earned in operant tests (g per $\mathrm{kg}$ body weight \pm s.e.m.). ${ }^{\star} P<0.05$ ( $n=8$ per group, ANOVA plus Bonferroni post hoc test). (d) Numbers of lever presses \pm s.e.m. over 30 min by WT and mutant mice on a fixed ratio 4 (FR4) schedule for sucrose-ethanol reinforcers. Note increased number of lever presses for mutants at reinforcer mixtures of $7 \%$ sucrose $/ 5 \%$ ethanol and $10 \%$ sucrose $/ 10 \%$ ethanol ( $n=8 /$ group). ${ }^{\star} P<0.05$, ANOVA plus Bonferroni post hoc test.

technique ${ }^{19,20}$. Self-administration of ethanol over $1 \mathrm{~h}$ caused ataxia, consistent with alcohol intoxication (Supplementary Fig. S5A). To determine whether the features of intoxication observed in mutant mice during the $1 \mathrm{~h}$ operant sessions were due to increased intake or a heightened sensitivity to alcohol, WT and mutant mice were given a standard body-weight-adjusted dose of ethanol and tested for the presence of ataxia on the rotarod (ethanol $3 \mathrm{~g}$ per $\mathrm{kg}$ ) and loss of righting reflex (ethanol $3.5 \mathrm{~g}$ per $\mathrm{kg}$; Supplementary Fig. S5). Although study groups were relatively small $(n=7-8)$, limiting statistical power, there was a strong tendency for the mutant mice to be more impaired than the WT mice (two-way ANOVA, main effect of genotype: $F(1,13)=4.46$; $P=0.05$ ), and to recover more slowly (two-way ANOVA, time point ${ }^{*}$ genotype interaction: $\left.F(1,13)=1.76 ; P=0.08\right)$. Genotype did not affect the rate of loss of righting reflex, but there was a trend towards a more rapid recovery in WT mice $(806 \pm 140$ versus $1466 \pm 448 \mathrm{~s}$ (mean \pm s.e.m.); $t$-test, $t=1.41 ; P<0.1)$. As neither the peak, nor time course of blood or brain alcohol levels differed significantly between mutant and WT mice following ethanol administration (Supplementary Fig. S6), these data suggest an increased sensitivity of $G a b r b 1^{+/ L 285 R}$ mice to the ataxic effects of ethanol (Supplementary Figs S5B,C and S6).

To ensure ataxia did not affect performance, we analysed only the first $30 \mathrm{~min}$ of each operant self-administration session. Although rates of lever pressing declined with lower sucrose and higher ethanol concentrations $(P<0.001$, two-way ANOVA $n=8$ per group), these were still higher with $7 / 5 \%$ and $10 / 10 \% v / v$ sucrose/ethanol (Fig. 1c,d) in Gabrb1 ${ }^{+/ L 285 R}$ mice compared with WT $(P<0.01$, two-way ANOVA $n=8$ per group). Above $5 \% v / v$ ethanol, mutant mice worked harder to obtain ethanol, irrespective of the sucrose concentration, tending towards lower lever-pressing rates for unadulterated sucrose $(P<0.1$, two-way
ANOVA $n=8$ per group). Thus, the Gabrb1 ${ }^{L 285 R}$ mutation is specific in affecting the motivation to consume alcohol.

Consistent with higher response rates, inter-response times (IRTs) were significantly shorter in the mutant mice (Supplementary Fig. S7). In order to obtain information on patterns of responding within a session, we analysed the pattern of IRTs within sessions. Interestingly, WT mice showed increases in IRTs as the session progressed, consistent with them satiating on alcohol. In contrast, the Gabrb1 ${ }^{+/ L 285 R}$ mice maintained their shorter IRTs (Supplementary Fig. S7). This pattern suggests that, in comparison with the WTs, their desire for alcohol decreased more slowly as they consumed alcohol.

Following the tests of alcohol self-administration, the mice were tested over two sessions in extinction (that is, lever pressing no longer resulted in fluid presentation). Their response rates declined when alcohol was no longer delivered following lever presses. The higher response rates maintained by Gabrb1 $+/ L 285 R$ mice during extinction sessions (Supplementary Fig. S8) were not significant, suggesting that there were no major differences in motivation to obtain ethanol under deprivation conditions. However, mice could not consume ethanol during extinction sessions and so any differences in rate of satiation to ethanol would not influence responding.

Mutant $\mathrm{GABA}_{\mathrm{A}} \mathrm{R} \beta 1$ subunits increase NAc tonic inhibition. The NAc is an important brain region for understanding the neurobiology of reward and addiction. Implicating $\mathrm{GABA}_{\mathrm{A}} \mathrm{Rs}$, specific suppression of either the $\mathrm{GABA}_{\mathrm{A}} \mathrm{R} \alpha 4$ or $\delta$ subunits in the NAc decreases both ethanol consumption and preference in rats $^{16,17}$. We therefore determined how the $\beta 1$ mutations affected $\mathrm{GABA}_{\mathrm{A}} \mathrm{R}$ function in NAc slices. Whole-cell voltage-clamp 
Table 1 | NAc tonic conductance.

\begin{tabular}{|c|c|c|c|c|}
\hline & WT & Gabrb1 $^{+/ L 285 R}$ & WT & Gabrb1 $^{+/ P 228 H}$ \\
\hline$I_{\mathrm{HOLD}}(\mathrm{pA})$ & $\begin{array}{c}212 \pm 24 \\
n=12\end{array}$ & $\begin{array}{c}284 \pm 14^{\star \star} \\
n=19\end{array}$ & $\begin{array}{c}156 \pm 12 \\
n=15\end{array}$ & $\begin{array}{c}296 \pm 20^{\star \star \star} \\
n=12\end{array}$ \\
\hline RMS (pA) (control) & $\begin{array}{c}4.3 \pm 0.2 \\
n=12\end{array}$ & $\begin{array}{c}7.9 \pm 0.2^{\star \star \star} \\
n=19\end{array}$ & $\begin{array}{c}3.9 \pm 0.1 \\
n=15\end{array}$ & $\begin{array}{c}7.0 \pm 0.2^{\star \star \star} \\
n=12\end{array}$ \\
\hline RMS $(p A)(+B i c)$ & $\begin{array}{c}2.7 \pm 0.2 \\
n=6\end{array}$ & $\begin{array}{c}4.4 \pm 0.2^{\star \star \star} \\
n=9\end{array}$ & $\begin{array}{c}2.6 \pm 0.1 \\
n=11\end{array}$ & $\begin{array}{c}3.5 \pm 0.1^{\star \star \star} \\
n=8\end{array}$ \\
\hline$\Delta$ RMS $(p A)(+B i c)$ & $\begin{array}{c}1.1 \pm 0.2 \\
n=6\end{array}$ & $\begin{array}{c}3.7 \pm 0.3^{\star \star \star} \\
n=9\end{array}$ & $\begin{array}{c}1.1 \pm 0.1 \\
n=11\end{array}$ & $\begin{array}{c}3.7 \pm 0.2^{\star \star \star} \\
n=8\end{array}$ \\
\hline$I_{\mathrm{BIC}}(\mathrm{pA})$ & $\begin{array}{c}22 \pm 3 \\
n=6\end{array}$ & $\begin{array}{c}120 \pm 8^{\star \star \star} \\
n=9\end{array}$ & $\begin{array}{l}22 \pm 3 \\
n=11\end{array}$ & $\begin{array}{c}115 \pm 9^{\star \star \star} \\
n=8\end{array}$ \\
\hline$I_{\mathrm{GBZ}}(\mathrm{pA})$ & $\begin{array}{l}17 \pm 4 \\
n=5\end{array}$ & $\begin{array}{c}19 \pm 3^{\dagger+\dagger} \\
n=4\end{array}$ & $\begin{array}{l}16 \pm 5 \\
n=4\end{array}$ & $\begin{array}{c}46 \pm 10^{\star, \dagger \dagger} \ddagger \\
n=3\end{array}$ \\
\hline I (pA) Bic + Ptx & $\begin{array}{c}27 \pm 5 \\
n=4\end{array}$ & $\begin{array}{c}171 \pm 8^{\star \star \star} \\
n=4\end{array}$ & $\begin{array}{c}20 \pm 10 \\
n=3\end{array}$ & $\begin{array}{c}137 \pm 26^{\star} \\
n=3\end{array}$ \\
\hline I (pA) Ptx after Bic & $\begin{array}{l}4 \pm 2 \\
n=4\end{array}$ & $\begin{array}{c}41 \pm 8^{\star \star} \\
n=4\end{array}$ & $\begin{array}{l}-5 \pm 3 \\
n=3\end{array}$ & $\begin{array}{c}19 \pm 6^{\star} \\
n=3\end{array}$ \\
\hline RMS (pA) (Bic + Ptx) & $\begin{array}{c}2.9 \pm 0.2 \\
n=4\end{array}$ & $\begin{array}{c}2.9 \pm 0.2 \\
n=4\end{array}$ & $\begin{array}{c}2.6 \pm 0.1 \\
n=3\end{array}$ & $\begin{array}{c}2.8 \pm 0.1 \\
n=3\end{array}$ \\
\hline$I_{\mathrm{THIP}}(\mathrm{pA})$ & $\begin{array}{c}60 \pm 15 \\
n=7\end{array}$ & $\begin{array}{l}41 \pm 9 \\
n=4\end{array}$ & ND & ND \\
\hline $\begin{array}{l}\text { Bic, bicuculline; Gbz, gabazine; } \\
\text { Statistical significance of muta } \\
\text { Statistical significance of } I_{G B Z} \\
\text { Statistical significance of Gabrt } \\
\text { Data presented as mean } \pm \text { s.e. }\end{array}$ & $\begin{array}{l}\text { picrotoxin } \\
0.05 ;{ }^{\star \star} P<0 \\
+\dagger \dagger P<0.001 \\
b 1^{+} / L 285 R \ddagger P\end{array}$ & 's t-test used in all & & \\
\hline
\end{tabular}

$(-60 \mathrm{mV})$ of $\mathrm{Gabrb1}{ }^{+/ L 285 R}$ NAc core MSNs revealed greater membrane current noise (root mean square (RMS)) and holding currents than for WT (Table 1). These effects were $G_{A B A} R$ mediated as the receptor antagonist bicuculline $(30 \mu \mathrm{M})$ induced an approximately sixfold greater outward current and a reduction in RMS for Gabrb1 $1^{+/ L 285 R}$ than for WT MSNs (Table 1, Fig. 2a,c).

Accumbal MSNs exhibit a GABA-dependent tonic conductance mediated by extrasynaptic $\alpha 4 \beta \delta$ receptors ${ }^{28}$. However, the inward current induced by the agonist THIP, at a $\delta$-GABA ${ }_{\mathrm{A}} \mathrm{R}$-selective concentration $(1 \mu \mathrm{M})$ was similar for WT and Gabrb1 ${ }^{+/ L 285 R}$ MSNs, implying that the large tonic current for $G a b r b 1^{+/ L 285 R}$ was not caused by increased $\delta-G A B A_{A} R$ expression (Table 1). In contrast to bicuculline (a partial negative allosteric modulator ${ }^{29-31}$ ), the competitive antagonist gabazine $(20 \mu \mathrm{M})$ only induced small outward currents in both WT and L285R MSNs (Table 1, Fig. 2c-e), suggesting increased ambient levels of agonist (for example, GABA, taurine) do not cause the larger tonic current.

The differential influence of $\mathrm{GABA}_{\mathrm{A}} \mathrm{R}$ antagonists on Gabrb1 ${ }^{+/ L 285 R}$ neurons may indicate that bicuculline, but not gabazine, shuts spontaneously open mutant $\beta 1 \quad \mathrm{GABA}_{\mathrm{A}} \mathrm{R}$ channels ${ }^{29,32}$. Indeed, picrotoxin $(100 \mu \mathrm{M})$, which is a noncompetitive antagonist of $\mathrm{GABA}_{\mathrm{A}} \mathrm{R}$-gated chloride channels, when co-applied with bicuculline, produced an additional outward current selectively in Gabrb1 $1^{+/ L 285 R}$ neurons (Table 1; Fig. 2c), whereas gabazine $(20 \mu \mathrm{M})$, which shares a common binding site with bicuculline, prevented the outward current induced by bicuculline $(30 \mu \mathrm{M})$, but not by picrotoxin $(100 \mu \mathrm{M}$; Table 1, Fig. 2d,e).

Gabrb1 $1^{+/ P 228 H}$ MSNs also exhibited a greater membrane current noise and holding current than WT MSNs (Table 1). In Gabrb1 $1^{+/ P 228 H}$ neurons, bicuculline $(30 \mu \mathrm{M})$ and, to a lesser extent, gabazine $(20 \mu \mathrm{M})$, induced larger outward currents relative to WT (Fig. 2b,c). In common with the $\beta 1 \mathrm{~L} 285 \mathrm{R}$ mutation, after gabazine, the co-application of picrotoxin $(100 \mu \mathrm{M})$ to Gabrb1 $1^{+/ P 228 H}$, but not to WT MSNs, induced an additional outward current (Fig. 2f,g). Furthermore, as for $\beta 1^{\mathrm{L} 285 \mathrm{R}}$, gabazine prevented the additional outward current produced by bicuculline in Gabrb1 $+/ P 228 H$ MSNs (Table 1; Fig. 2f). Thus, Gabrb1 ${ }^{P 228 H}$ enhanced the tonic conductance, consistent with the ability of these mutant $\beta 1 \mathrm{GABA}_{\mathrm{A}} \mathrm{Rs}$ to open spontaneously.

ß1 subunit mutations influence NAc phasic inhibition. The $\beta 1$ subunit mutations also affected $\mathrm{GABA}_{\mathrm{A}} \mathrm{R}$-mediated phasic inhibition. For Gabrb1 $1^{+/ L 285 R}$ and Gabrb1 $1^{+/ P 228 H}$ MSNs the frequency of mIPSCs was reduced and their decay times prolonged. Additionally, the mIPSC amplitude was increased for Gabrb1 ${ }^{+/ L 285 R}$ relative to WT MSNs (Fig. 2h,i; Table 2), which was associated with an increased population of large amplitude mIPSCs, exhibiting slow decays. A scatter plot revealed a cluster of large amplitude (peak amplitude $>105 \mathrm{pA}$ ), slowly decaying (T70 > $19 \mathrm{~ms}$ ) events prevalent in Gabrb1 ${ }^{+/ L 285 R}$ MSNs constituting only $0.7 \%$ of the total number of events for WT MSNs, but $8.8 \%$ ( $>10$-fold increase) of the Gabrb1 ${ }^{+/ L 285 R}$ MSNs (Supplementary Fig. S9). Conversely, the proportion of events with a peak amplitude $<105 \mathrm{pA}$ and T70 $<19 \mathrm{~ms}$ decreased from $81.7 \%$ for WT to $54.2 \%$ for the Gabrb1 ${ }^{+/ L 285 R}$ MSNs. This loss is accounted for not only by the greater percentage of events with a peak amplitude $>105 \mathrm{pA}$ and T70 $>19 \mathrm{~ms}$ but, additionally, by a higher proportion of events with an amplitude $>105 \mathrm{pA}$ (T70 $\leq 19 \mathrm{~ms}$ ) and of those with a T70 $>19 \mathrm{~ms}$ (but pA $\leq 105 \mathrm{pA}$ ) (Supplementary Fig. S9). Such events may originate from a population of mutant postsynaptic $\beta 1-\mathrm{GABA}_{\mathrm{A}} \mathrm{Rs}$, with increased open probabilities compared with WT $\beta 1-G_{A B A}$ Rs.

Both the L285R and the $\mathrm{P} 228 \mathrm{H}$ mutations were associated with a reduced mIPSC frequency compared with WT counterparts (Supplementary Table S2). Activation by THIP of presynaptic $\delta$-GABA $\mathrm{A}$ Rs, located either on accumbal interneurons (the main source of MSN somatic input) or on neighbouring MSNs, reduces GABA release onto MSNs (mIPSC frequency, control: $1.9 \pm 0.2 \mathrm{~Hz}$; + THIP $1 \mu \mathrm{M}: 1.1 \pm 0.2 \mathrm{~Hz}$, data presented as mean \pm s.e.m., $n=5 ; P<0.05$ paired $t$-test). Therefore, it is conceivable that pre-synaptically located spontaneously open 
a

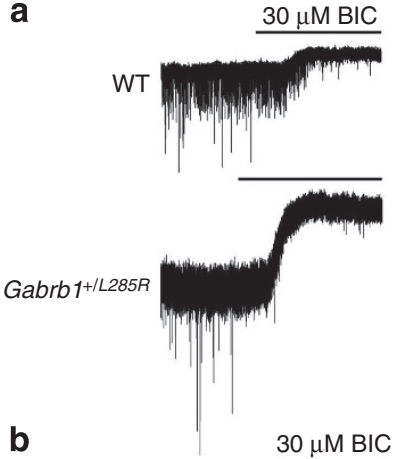

b

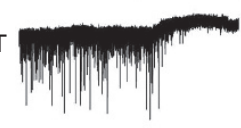

c

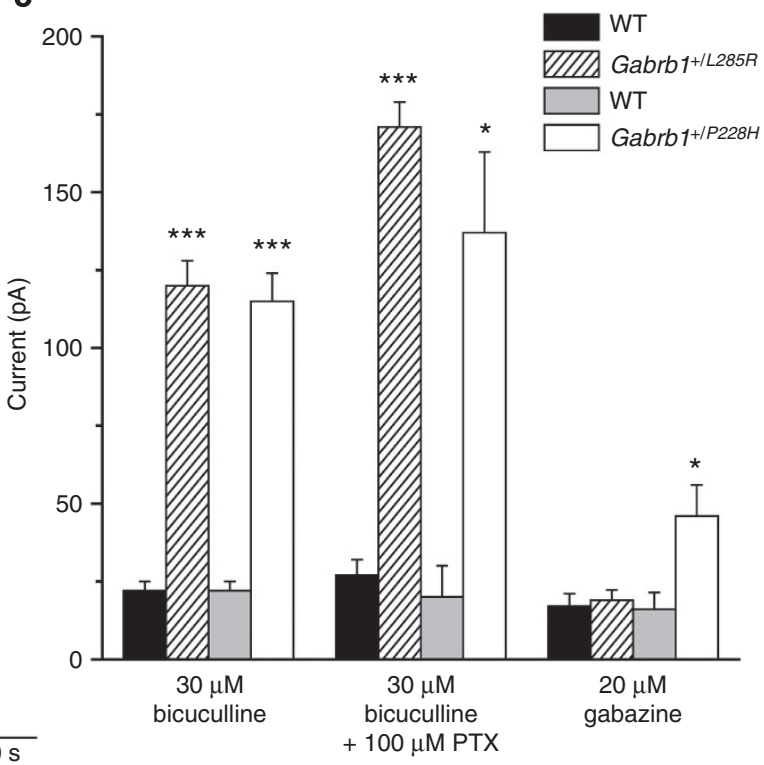

d

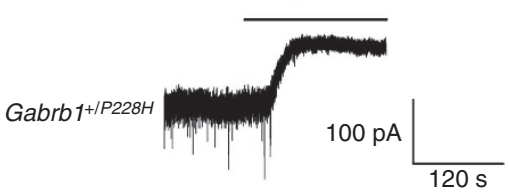

e

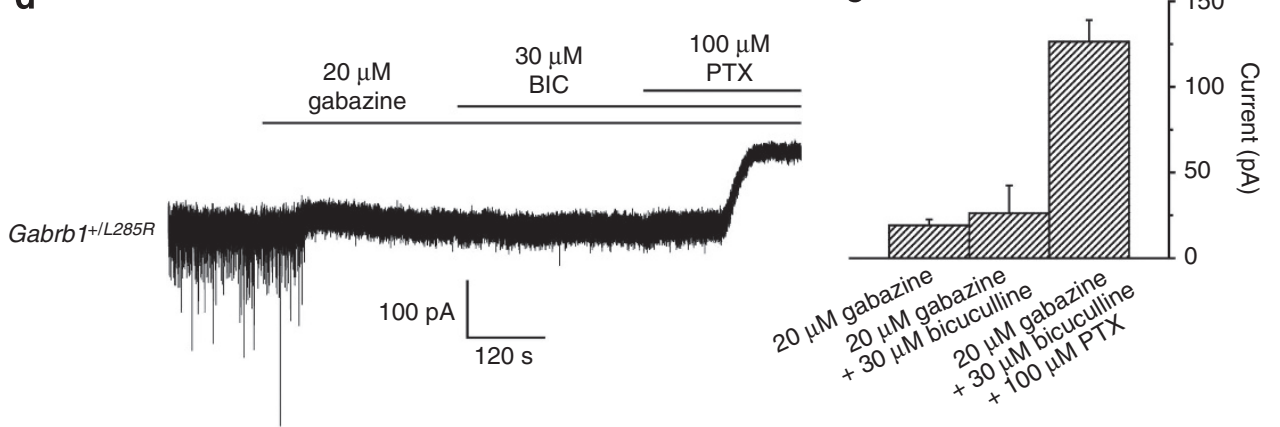

f
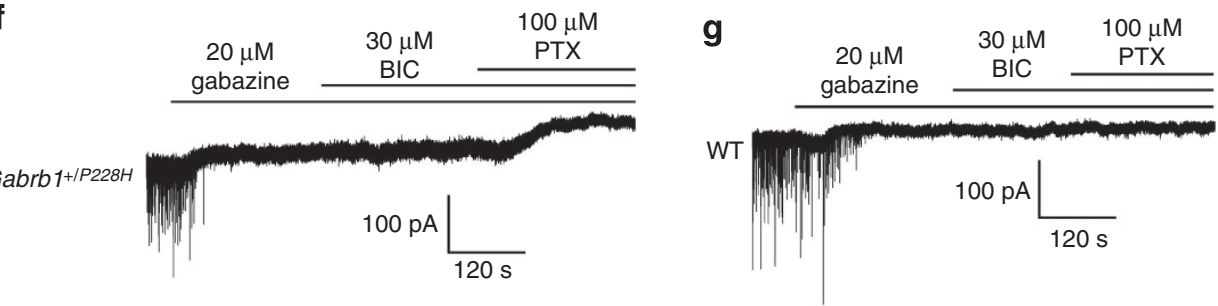

h
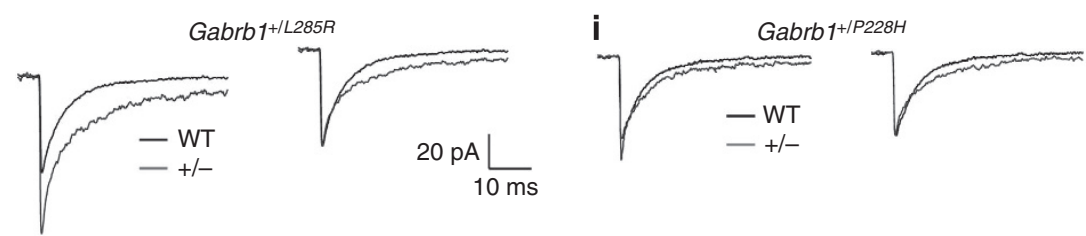

Figure 2 I $\beta 1$ mutations influence tonic and phasic inhibition of MSNs. Whole-cell recordings from accumbal MSNs of Gabrb1 $+/ L 285 R$ (a), Gabrb1 $+/ P 228 H$ (b) and WT littermates. Note for both Gabrb1 $1^{+/ L 285 R}$ and Gabrb1 ${ }^{+/ P 228 H}$ MSNs the larger outward currents produced by bicuculline $(30 \mu M)$. Scale bars apply to both $\mathbf{a}$ and $\mathbf{b}$. (c) Outward currents induced by bicuculline $(30 \mu \mathrm{M})$, gabazine $(20 \mu \mathrm{M})$ and picrotoxin $(\mathrm{PTX}, 100 \mu \mathrm{M})$ from WT, Gabrb1 $+/ L 285 R$ and Gabrb1+/P228H MSNs (means \pm s.e.m.; $n=3-12$ ). (d) Whole-cell recording from a Gabrb1+/L285R MSN. Gabazine $(20 \mu M)$ abolishes the mIPSCs, but produces only a relatively small outward current. However, gabazine prevents the further outward current usually produced by bicuculline for this mutant, but not that produced by picrotoxin. (e) Mean outward current induced by GABA $\mathrm{R}$ antagonists for Gabrb1 ${ }^{+/ L 285 R}$ MSNs (means \pm s.e.m.; $n=4)$. Whole-cell recordings from a Gabrb1 $+/ P 228 H$ (f) and a WT MSN $(\mathbf{g})$. Gabazine $(20 \mu \mathrm{M})$ abolishes mIPSCs, but additionally produces only a relatively small outward current for both the Gabrb1 $+/ P 228 \mathrm{H}$ and WT MSNs. However, for the Gabrb1 $+/ P 228 \mathrm{H}$ MSN gabazine prevents a further outward current by subsequent bicuculline, but this antagonist does not prevent the outward current produced by picrotoxin. By contrast, for WT MSNs after gabazine both bicuculline and picrotoxin are inert. Superimposed averaged mIPSCs are shown for WT (black) and Gabrb1 ${ }^{+/ L 285 R}$ (h), or Gabrb1 ${ }^{+/ P 228 H}$ (i) MSNs (grey). Right-hand traces of each pair are normalized to the mean peak amplitude of the appropriate WT mIPSC. Note the prolonged mIPSCs for Gabrb1 ${ }^{+/ L 285 R}$ and Gabrb1 ${ }^{+/ P 228 H}$ over WT. Scale bars apply to both $\mathbf{h}$ and $\mathbf{i}$. ${ }^{\star} P<0.05,{ }^{\star \star \star} P<0.001$ (unpaired Student's $t$-test for mutants relative to WTs). 
Table 2 | Brain slice electrophysiology: synaptic transmission.

\begin{tabular}{|c|c|c|c|c|}
\hline & $\begin{array}{c}\text { WT } \\
n=12\end{array}$ & $\begin{array}{c}\text { Gabrb1 }+/ \text { L285R } \\
n=13\end{array}$ & $\begin{array}{c}\text { WT } \\
n=6\end{array}$ & $\begin{array}{c}\text { Gabrb1 }^{+/ P 228 H} \\
n=7\end{array}$ \\
\hline Peak Amp. (pA) & $62 \pm 4$ & $88 \pm 6^{\star \star}$ & $53 \pm 2$ & $64 \pm 5$ \\
\hline Rise time (ms) & $0.5 \pm 0.02$ & $0.5 \pm 0.02$ & $0.6 \pm 0.02$ & $0.5 \pm 0.02$ \\
\hline Frequency $(\mathrm{Hz})$ & $2.1 \pm 0.5$ & $0.6 \pm 0.1^{\star \star}$ & $2.9 \pm 0.5$ & $0.8 \pm 0.02^{\star \star \star}$ \\
\hline
\end{tabular}

$\beta 1-\mathrm{GABA}_{\mathrm{A}} \mathrm{Rs}$ either on interneurons or neighbouring MSNs would similarly influence GABA release, thereby reducing MSN mIPSC frequency.

Mutant $\beta 1$ subunit expression and spontaneous channel opening. To explore how the $\beta 1^{\mathrm{L} 285 \mathrm{R}}$ and $\beta 1^{\mathrm{P} 228 \mathrm{H}}$ mutations affected $\mathrm{GABA}_{\mathrm{A}} \mathrm{R}$ function, we used heterologous expression of WT and mutant recombinant $\mathrm{GABA}_{\mathrm{A}} \mathrm{Rs}$ in HEK293 cells. Immunocytochemistry was used to assess the expression levels of myc epitope-tagged WT and mutant $\beta 1$ subunits. The expression levels of $\beta 1^{\mathrm{L} 285 \mathrm{R}}$ along with $\alpha 2$ and $\gamma 2 \mathrm{~L}$ subunits, including enhanced green fluorescent protein (eGFP), revealed no differences either for cell surface or overall total fluorescence (Supplementary Fig. S10). Similarly, the cell surface membrane and intracellular expression levels for $\beta 1^{\mathrm{P} 228 \mathrm{H}}$ were also unaltered compared with WT $\beta 1$ subunits (Supplementary Fig. S11).

To examine whether the $\beta 1$ subunit mutations (L285R and $\mathrm{P} 228 \mathrm{H}$ ) altered $\mathrm{GABA}_{\mathrm{A}} \mathrm{R}$ receptor physiology and pharmacology, whole-cell recording was performed on $\alpha 2 \beta 1^{\mathrm{L} 285 \mathrm{R}} \gamma 2$ and $\alpha 2 \beta 11^{\mathrm{P} 228 \mathrm{H}} \gamma 2$ receptors expressed in HEK293 cells. Relative to WT, both mutations reduced the maximum current density induced by saturating GABA concentrations ( $1 \mathrm{mM}$; Fig. 3a).

As native $G_{A B A}$ Rs contain two $\beta$ subunits and because our in vivo studies necessarily used heterozygous mice, a proportion of native $\mathrm{GABA}_{\mathrm{A}}$ Rs could comprise a mixture of WT and mutant $\beta 1$ subunits. To examine the amplitudes of GABA-evoked currents under these conditions, we recreated a binomial mixture of $\mathrm{GABA}_{\mathrm{A}}$ Rs in HEK293 cells by co-expressing $\alpha 2$ and $\beta 1$ with either $\beta 1^{\mathrm{L} 285 \mathrm{R}}$ or $\beta 1^{\mathrm{P} 228 \mathrm{H}}$ and $\gamma 2$ subunits in an equimolar ratio, thereby reproducing native receptor isoforms likely to be present in heterozygotes. Assuming receptor subunit assembly proceeds according to binomial probabilities, we would expect a mixture of pentameric receptors $(2 \alpha: 2 \beta: 1 \gamma)$ to include: WT, full mutant (both $\beta$ subunits are mutated) and two forms of partial mutant receptors containing only one copy of the mutant $\beta$ subunit. The maximum current densities induced by saturating concentrations of GABA (up to $1 \mathrm{mM}$ ) were larger for receptors containing only one copy of the mutant $\beta$ subunit than those observed with full mutant receptors, and this approached that of WT receptors (Supplementary Fig. S12).

GABA concentration-response curves revealed that GABA potency was increased $(\sim 2-3$-fold $)$ by $\beta 1^{\mathrm{L} 285 \mathrm{R}}$ and $\beta 1^{\mathrm{P} 228 \mathrm{H}}$ (Fig. 3b,d; Supplementary Table S4). Significantly, the holding current (at $-40 \mathrm{mV}$ ) was greater for many mutant receptorexpressing cells compared with WT (Supplementary Table S4), indicative of spontaneous GABA channel activity ${ }^{33}$. Indeed, picrotoxin $(100 \mu \mathrm{M})$ induced outward currents in the absence of GABA for cells expressing $\beta 1^{\mathrm{L} 285 \mathrm{R}}$, and to a lesser extent for $\beta 1^{\mathrm{P} 228 \mathrm{H}}$ mutant receptors, reflecting spontaneous channel activity (Fig. 3c). The spontaneous current revealed by picrotoxin $\left(I_{\mathrm{PTX}}\right)$ accounted for $\sim 3-15 \%$ of the total current $\left(=I_{\mathrm{GABA}, \max }+I_{\mathrm{PTX}}\right)$ for these mutant receptors.
We also examined the level of spontaneous current for $\alpha 4 \beta 1 \gamma 2$ receptors, with WT or mutant $\beta 1$ subunits, as an alternative isoform that may populate synaptic and/or extrasynaptic sites. Maximal current densities and holding currents exhibited greater variability for the $\beta 1$ mutants compared with WT (Supplementary Table S4), and $\alpha 4 \beta 1^{\mathrm{L} 285 \mathrm{R}} \gamma 2$ exhibited a spontaneous current revealed by picrotoxin (Fig. 3c).

To examine the gating of GABA ion channels underlying the spontaneous current, we used outside-out patches from HEK293 cells expressing $\alpha 2 \beta 1 \gamma 2, \alpha 2 \beta 1^{\mathrm{L} 285 \mathrm{R}} \gamma 2$ or $\alpha 2 \beta 1^{\mathrm{P} 228 \mathrm{H}} \gamma 2$ receptors (Fig. 3e). Spontaneous channel activity was evident with mutant receptors, but absent in WT, and abolished by the GABA antagonist, bicuculline $(50 \mu \mathrm{M})$, acting as a negative allosteric modulator $^{29}$ in the absence of GABA. Activating WT $\alpha 2 \beta 1 \gamma 2$ GABA channels with $10 \mu \mathrm{M}$ GABA induced single-channel currents that were indistinguishable from the spontaneous openings observed with the mutant receptors (Fig. 3e) and with only minor differences in open and shut time durations (Supplementary Table S5). Overall, $\beta 1^{\mathrm{L} 285 \mathrm{R}}$, but to a lesser extent, $\beta 1^{\mathrm{P} 228 \mathrm{H}}$ caused spontaneous channel opening and increased receptor sensitivity to GABA when co-assembled with either $\alpha 2$ or $\alpha 4$ and $\gamma 2$ subunits.

Given the importance of $\alpha 4$ and $\delta$ subunits for tonic current in NAc MSNs ${ }^{16,17,28}$ we explored whether $\beta 1$ mutants also conferred spontaneous channel activity on $\delta$-GABA $A_{A}$ Rs. Using HEK293 cells, $\beta 1$ subunits were expressed with either $\alpha 2$ (colocated on same chromosome as $\beta 1$, and expressed in accumbal synapses ${ }^{34}$ ), or $\alpha 4$ (co-expressed in the accumbens with $\delta$ forming extrasynaptic receptors) ${ }^{28}$. The $\beta 1^{\mathrm{L} 285 \mathrm{R}}$ mutation increased the maximum current density to saturating GABA $(300 \mu \mathrm{M})$ for both $\alpha 2 \beta 1^{\mathrm{L} 285 \mathrm{R}} \delta$ and $\alpha 4 \beta 1^{\mathrm{L} 285 \mathrm{R}} \delta$ receptors, compared with WT equivalents $(\alpha 2 / 4 \beta 1 \delta)$, whereas $\beta 1^{\mathrm{P} 228 \mathrm{H}}$ did not (Supplementary Fig. S13). Both $\beta 1$ mutants increased

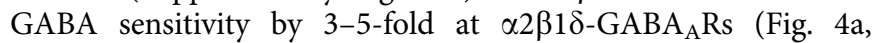
Supplementary Table S4), similar to the increased sensitivity for mutant $\alpha 2 \beta 1 \gamma$ GABA $_{\mathrm{A}}$ Rs (Fig. 3b), but only $\beta 1^{\mathrm{L} 285 \mathrm{R}}$ affected $\alpha 4 \beta 1 \delta$ receptor sensitivity to GABA (Fig. $4 \mathrm{~b}$ ).

In the absence of GABA, picrotoxin $(100 \mu \mathrm{M})$ induced outward currents only for $\alpha 2 / 4 \beta 1^{\mathrm{L}_{285 R}} \delta \mathrm{GABA}_{\mathrm{A}} \mathrm{Rs}$ (Fig. $4 \mathrm{c}, \mathrm{d}$ ), with $\alpha 2 / 4 \beta 1^{\mathrm{P} 228 \mathrm{H}} \delta$ showing similar levels of activity to WT. Given that $\beta 1^{\mathrm{L} 285 \mathrm{R}}$ conferred substantial spontaneous activity on $\delta$-GABA $\mathrm{A}$ Rs, compared with $\beta 1^{\mathrm{P} 228 \mathrm{H}}$, the increased tonic currents recorded in MSNs of the NAc and caused by the $\beta 1$ mutants are most likely due to the presence of $\alpha 2 / 4 \beta 1^{\mathrm{L} 285 \mathrm{R}} \gamma 2, \alpha 2 /$ $4 \beta 1^{\mathrm{P} 228 \mathrm{H}} \gamma 2$ and $\alpha 2 / 4 \beta 1^{\mathrm{L} 285 \mathrm{R}} \delta$ isoforms.

Alcohol and $\mathrm{GABA}_{\mathbf{A}}$ Rs. Although alcohol may directly modulate some $\mathrm{GABA}_{\mathrm{A}} \mathrm{Rs}$, this remains controversial ${ }^{21,22,35,36}$. Here ethanol (30-200 mM) co-applied with low concentrations $\left(\mathrm{EC}_{10}\right)$ of GABA did not modulate $\alpha 2 / \alpha 4 \beta 1 \gamma 2 \quad \mathrm{GABA}_{\mathrm{A}} \mathrm{Rs}$ containing either WT or mutant $\beta 1$ subunits in HEK cells (Supplementary Table S4). Alcohol intoxication is associated with increased production of the endogenous neurosteroid 

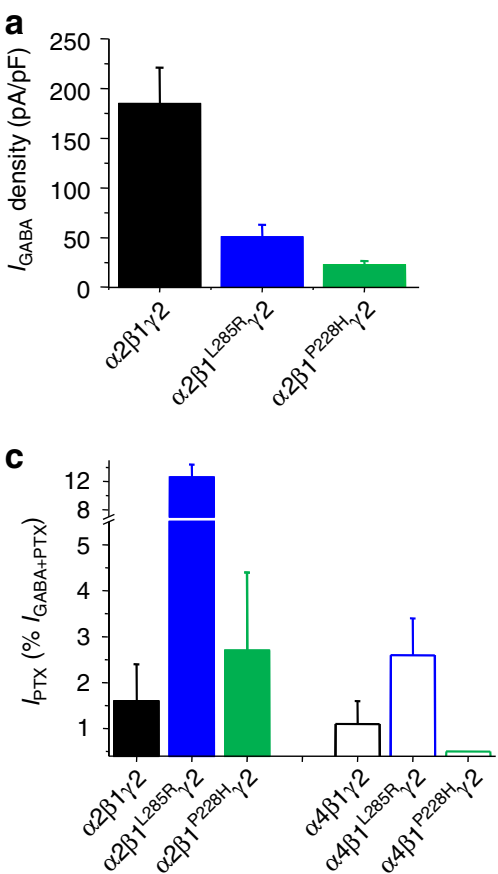

b

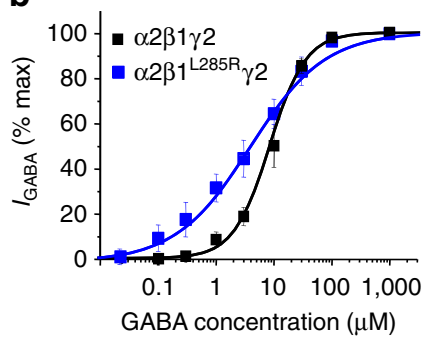

d

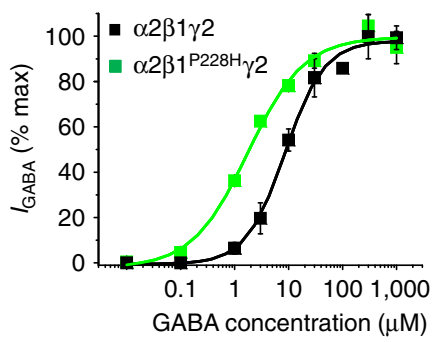

e

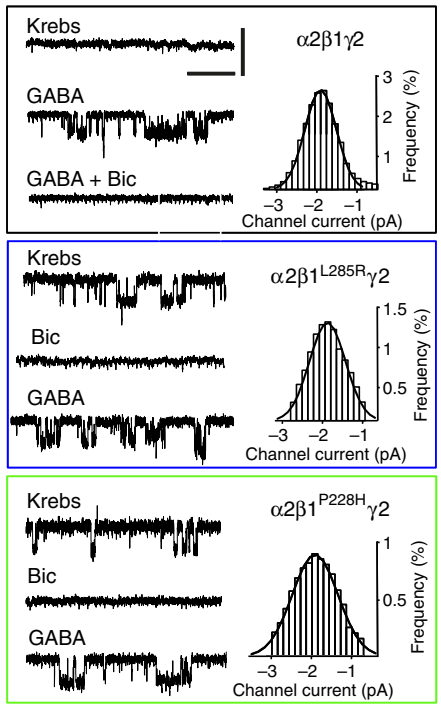

Figure 3 | Effects of $\boldsymbol{\beta 1}^{\mathbf{L 2 8 5 R}}$ and $\boldsymbol{\beta 1}^{\mathbf{P 2 2 8 H}}$ on recombinant $\mathbf{G A B A} \mathbf{A} \mathbf{R s}$. (a) Mean maximal GABA current densities to saturating GABA concentrations for WT and mutant, $\alpha 2 \beta 1 \gamma 2$ receptors. (b) GABA concentration-response curves for WT and $\alpha 2 \beta 1^{1285 R} \gamma 2$ receptors. Responses are normalized to the maximum response from each cell. (c) Mean maximal outward currents produced by picrotoxin (PTX; $100 \mu \mathrm{M}$ ) for WT and mutant receptors. Values are percentages of total current $\left(=I_{\text {PTX }} /\left(I_{\text {PTX }}+I_{\text {GABA Max }}\right)\right.$. (d) GABA concentration-response curves for WT and $\alpha 2 \beta 1^{\mathrm{P} 228 \mathrm{H}} \gamma 2$ receptors, analysed as in (b). (e) Single channel currents (sampled at $50 \mathrm{kHz}$ ) from outside-out patches ( $-70 \mathrm{mV}$ ) of HEK293 cells expressing $\alpha 2 \beta 1 \gamma 2, \alpha 2 \beta 1^{\mathrm{L} 285 \mathrm{R}} \gamma 2 \mathrm{2}$ and $\alpha 2 \beta 1^{\mathrm{P} 228 \mathrm{H}} \gamma 2$ receptors. Spontaneous channel activity is evident in the absence of GABA (traces labelled 'Krebs'). Both spontaneous and GABA-activated channel openings are inhibited by bicuculline (Bic: $50 \mu \mathrm{M}$ ). Scale bars: $2 \mathrm{pA}, 100 \mathrm{~ms}$. Single channel amplitude histograms (right panels) are based on $10-30$ s epochs for $\alpha 2 \beta 1 \gamma 2$ (activated by $10 \mu \mathrm{M} \mathrm{GABA}$ ) and for spontaneously active $\alpha 2 \beta 1^{\mathrm{L} 285 \mathrm{R}} \gamma 2$ and $\alpha 2 \beta 1^{\mathrm{P} 228 \mathrm{H}} \gamma 2$. All single channel currents have mean amplitudes of approximately $-1.9 \mathrm{pA}(\sim 27 \mathrm{pS})$. Error bars in panels a-d represent the mean \pm s.e.m. $(n=7-15$ for $\mathbf{a}: n=4-6$ for panels $\mathbf{b}$ and $\mathbf{d}: n=6-11$ for $\mathbf{c}$ ).

allopregnanolone, an allosteric potentiator of $\mathrm{GABA}_{\mathrm{A}} \mathrm{Rs}^{35}$. However, WT and $\beta 1$ mutant $\mathrm{GABA}_{\mathrm{A}} \mathrm{Rs}$ remained equally sensitive to potentiation by allopregnanolone $(1 \mu \mathrm{M})$ and benzodiazepines $\left(0.5 \mu \mathrm{M}\right.$ diazepam), and to inhibition by $\mathrm{Zn}^{2}+(100 \mu \mathrm{M})$ or bicuculline $(50 \mu \mathrm{M})$ (Supplementary Figs S14 and S15). Similarly, neither $\beta 1$ mutant when co-expressed with $\alpha 2 \delta$ or $\alpha 4 \delta$ subunits demonstrated sensitivity to 30 or $100 \mathrm{mM}$ ethanol (Fig. 4e). Potentiation of $\alpha \beta \delta \mathrm{GABA}_{\mathrm{A}} \mathrm{R}$ function by neurosteroids (THDOC) was also unaffected by the mutation (Supplementary Fig. S13). A previous study in the dorsal striatum clearly demonstrated that acute ethanol decreased the amplitude of the electrically evoked IPSCs recorded from MSNs of young rats, but with no effect on the paired pulse ratio, suggesting a postsynaptic locus ${ }^{37}$. However, in our recordings from mature mouse NAc MSNs, ethanol $(50 \mathrm{mM})$ had no significant effect on the spontaneous IPSCs (paired recordings $n=5$ neurons from 5 mice per genotype; Supplementary Fig. S16). Note that although there was an apparent trend for ethanol to increase the frequency of sIPSCs in the Gabrb1 $1^{+/ L 285 R}$ MSNs, it was not significant in this sample. In further agreement with the recombinant receptor experiments, ethanol $(50 \mathrm{mM})$ had no effect on the holding current of WT or Gabrb1 $1^{+/ L 285 R}$ MSNs (paired recordings $n=5$ neurons from 5 mice per genotype; Supplementary Fig. S16). Thus, it is evident that the L285R and P228H mutations do not affect the co-assembly of $\beta 1$ with $\alpha 2 / 4, \delta$ and $\gamma 2$ subunits, or their pharmacological properties.

\section{Discussion}

ENU mutagenesis ${ }^{25}$ of alcohol-averse BALB/cAnN mice generated a stable line carrying a non-synonymous dominant mutation in Gabrb1 (L285R) with a strong phenotypic preference for alcohol. Given that the probability of a second ENU-induced mutation within a $5-\mathrm{Mb}$ region is estimated to be $P<0.002$ (using both a Maximum Likelihood Estimation method, adopting a Poisson model, and a Markov chain Monte Carlo method, with a Poisson Gamma model) ${ }^{38,39}$, the probability of a second functional mutation within the $1.6-\mathrm{Mb}$ genomic region of interest is extremely remote and would continue to halve with each of the subsequent eight backcross generations that have been studied. This possibility has been further excluded by the absence of other exonic mutations following comparative sequencing across the candidate region. Importantly, the identification of a second, independent line with a spontaneous, nonsynonymous single base-pair mutation $(\mathrm{P} 228 \mathrm{H})$ in the same gene that also consistently exhibits ethanol preference and similar phenotypic traits over the five backcross generations studied, provides further confirmation that the phenotype is caused by mutating Gabrb1.

Mutant and WT mice showed no differences in preference for saccharin or quinine solutions, discounting taste as a driver for high alcohol consumption by the mutants. That Gabrb1 ${ }^{+/ L 285 R}$ mice worked harder than WT to obtain alcohol compared with sucrose solutions indicates that motivation for alcohol was also not driven by calorific requirement or taste. Importantly, mutants undertook this extra work despite possessing lower body weights than their WT counterparts. The mutant mice also showed greater sensitivity to the sedative/ataxic effects of ethanol, which together with increased consumption, contributed to an increased incidence of intoxication. 

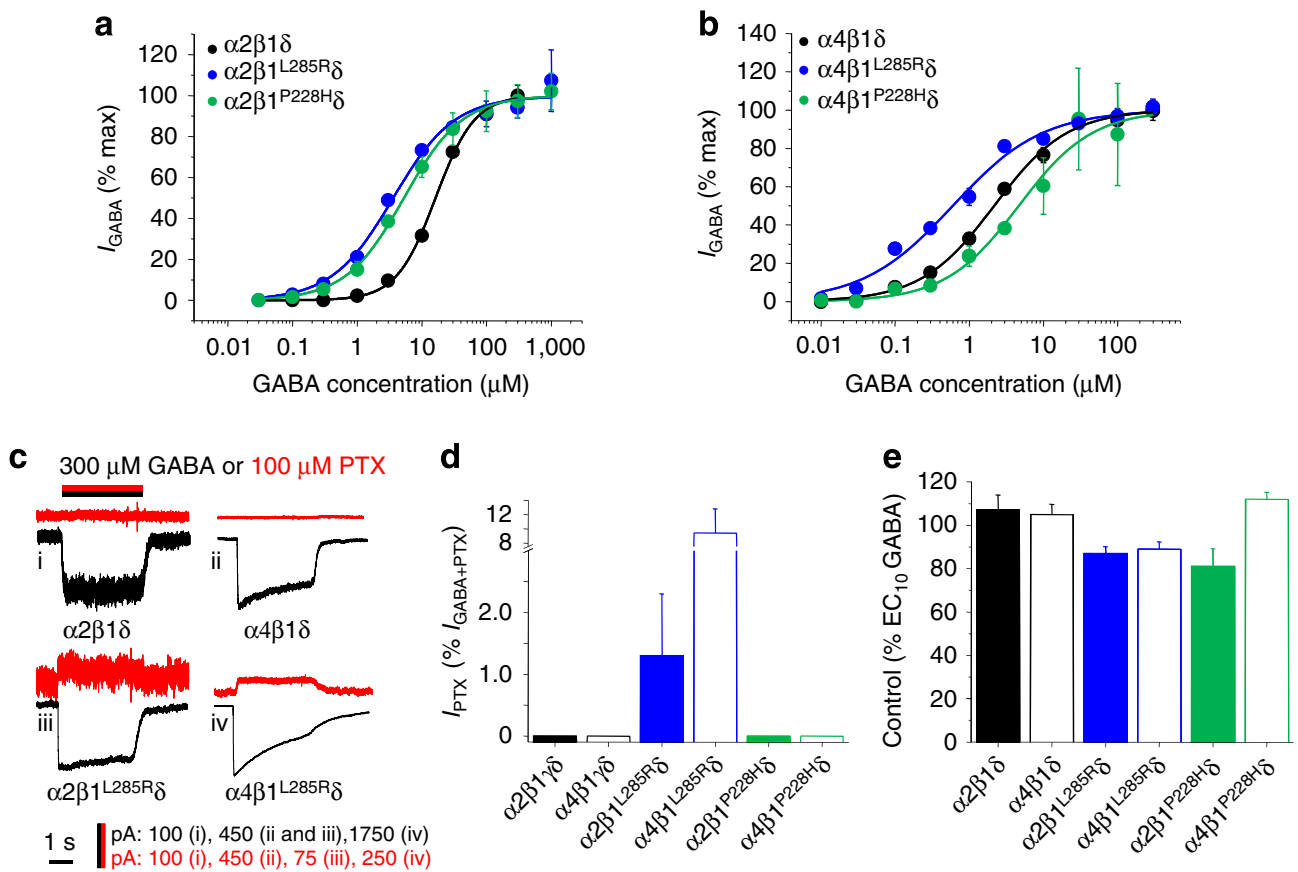

Figure 4 | Effects of $\boldsymbol{\beta 1}^{\mathbf{L 2 8 5 R}}$ and $\boldsymbol{\beta} \mathbf{P}^{\mathbf{P 2 2 8 H}}$ on $\boldsymbol{\delta}$-containing recombinant $\mathbf{G A B A} \mathbf{A}_{\mathbf{A}} \mathbf{R s}$. (a,b) GABA concentration-response curves for WT and mutant $\alpha 2 \beta 1 \delta$ and $\alpha 4 \beta 1 \delta$ receptors, analysed as in Fig. 3b. (c) Representative membrane currents for GABA (black) or picrotoxin (red) recorded for WT and mutant (L285R) $\alpha 2 \beta 1 \delta$ and $\alpha 4 \beta 1 \delta$ receptors $\left(V_{H}=-40 \mathrm{mV}\right.$ ). (d) Mean maximal outward currents after PTX (100 $\mu \mathrm{M}$; expressed as in Fig. 3c) applied in the absence of GABA for WT and mutant $\alpha 2 \beta 1 \delta$ (solid bar) or $\alpha 4 \beta 1 \delta$ (open bar) receptors. (e) Mean GABA responses (EC 10 ) in the presence of $30 \mathrm{mM}$ EtOH for $\mathrm{WT}$ and mutant receptors (Control $\mathrm{EC}_{10}$ responses $\left.=100 \%\right)$. All error bars in $\mathbf{a}, \mathbf{b}, \mathbf{d}$ and e represent the mean \pm s.e.m. $(n=5-12$ for $\mathbf{a}$ and $\mathbf{b}: n=7-12$ for $\mathbf{d}: n=3-13$ for $\mathbf{e}$ ).

Previous studies in man demonstrated significant allelic association between the risk of alcohol dependence and GABRA2 and GABRB1 polymorphisms s $^{4,50-42}$. Although deleting Gabra2 in mice did not alter ethanol self-administration ${ }^{19}$, and human polymorphisms and mouse mutations may lack common effects on receptor function, our studies are supportive of the view that the $\mathrm{GABA}_{\mathrm{A}} \mathrm{R} \beta 1$ subunit is a modifier of alcohol consumption.

The NAc is associated with reward and has an important role in addiction. Our recordings from MSNs within the accumbal core revealed that the $\beta 1$ subunit mutations greatly impact upon both synaptic and tonic inhibitory transmission. For

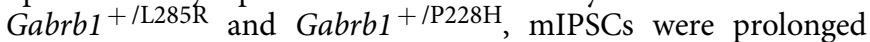
and less frequent. Given our previous demonstration that MSNs express synaptic $\alpha 2-\mathrm{GABA}_{\mathrm{A}} \mathrm{Rs}^{34}$, the changed mIPSC kinetics suggest that $\beta 1$ subunits may co-assemble with $\alpha 2$ and $\gamma_{2}$ subunits at inhibitory synapses. The $\mathrm{GABA}_{\mathrm{A}} \mathrm{R}$-mediated tonic conductance was greatly increased in the NAc of Gabrb1 ${ }^{+/ L 285 R}$ and Gabrb1 $1^{+/ P 228 H}$ mice. The differential effects of $\mathrm{GABA}_{\mathrm{A}} \mathrm{R}$ antagonists suggest that this perturbation results from spontaneous activity of mutant $\beta 1-\mathrm{GABA}_{\mathrm{A}} \mathrm{Rs}$, though increased receptor sensitivity to GABA and, for Gabrb1 ${ }^{+/ P 228 H}$, an increase in ambient GABA may also contribute.

Our recombinant receptor studies indicate that mutant $\beta 1$ subunits efficiently co-assemble with $\alpha$ and $\gamma$ or $\delta$ subunits and are functionally expressed at the cell surface, with minimal effect on their pharmacological properties. Nevertheless, both $\beta 1^{\mathrm{P} 228 \mathrm{H}}$ and $\beta 1^{\mathrm{L} 285 \mathrm{R}}$ mutations increased receptor sensitivity to GABA and caused their channels to open spontaneously in the absence of GABA, particularly for L285R. Modelling the likely subunit combinations of synaptic $\alpha 2$ - and extrasynaptic $\delta$-containing $\mathrm{GABA}_{\mathrm{A}} \mathrm{Rs}$ found in accumbal MSNs, we recreated recombinant equivalents of extrasynaptic $(\alpha 2 / 4 \beta 1 \delta)$ and synaptic $(\alpha 2 / 4 \beta 1 \gamma 2)$ type receptors. Mutating the $\beta 1$ subunit initiated spontaneous
GABA channel opening, with $\beta 1^{\mathrm{L} 285 \mathrm{R}}$ exhibiting a greater degree of spontaneous activity, implying that both $\alpha \beta 1^{\mathrm{L} 285 \mathrm{R}} \gamma$ and $\alpha \beta 11^{\mathrm{L} 285 \mathrm{R}} \delta$ receptors are the most significant contributors to the increased spontaneous (tonic) current in the NAc of the Gabrb1 ${ }^{+/ L 285 R}$ mouse. In comparison, $\beta 1^{\mathrm{P} 228 \mathrm{H}} \mathrm{GABA}_{\mathrm{A}} \mathrm{Rs}$ were less spontaneously active, but such activity was nevertheless clearly evident for $\alpha 2 \beta 1^{\mathrm{P} 228 \mathrm{H}_{\gamma 2}}$.

Recombinant $\mathrm{GABA}_{\mathrm{A}} \mathrm{Rs}(\alpha 2 / \alpha 4 \beta 1 \gamma 2, \alpha 2 / \alpha 4 \beta 1 \delta)$ incorporating either WT or mutant $\beta 1$ subunits were consistently insensitive to ethanol. Similarly, neither tonic nor phasic inhibition of WT and $\beta 1$ mutant MSNs was affected by ethanol. Although low ethanol concentrations $(\sim 10-30 \mathrm{mM})$ have been reported to enhance neuronal and recombinant $\delta$-GABA $\mathrm{A}^{21,23}$ function, other studies have failed to corroborate such effects ${ }^{22,24,43-45}$.

Thus, increased accumbal tonic current is associated with $\beta 1$ subunit mutations leading to increased ethanol consumption, but not as a consequence of direct effects of ethanol on $\mathrm{GABA}_{\mathrm{A}} \mathrm{Rs}$. Notably, both ethanol preference and consumption are reduced in $\delta^{-l}-$ mice $^{18}$, a genetic manipulation that reduces accumbal tonic currents ${ }^{28}$. The importance of the tonic current for ethanol reward is emphasized by RNAi knockdown of either $\alpha 4$ or $\delta$ subunits in the accumbens, which reduced ethanol consumption and preference without affecting water or sucrose intake $e^{16,17}$. Collectively, this strongly suggests that the large tonic conductance of MSNs contributes to the increased preference and intake of alcohol by Gabrb1 $1^{+/ L 285 R}$ and Gabrb1+/P228H mice.

Our study identifies $\mathrm{GABA}_{\mathrm{A}}$ Rs containing the $\beta 1$ subunit as a key element in modulating alcohol consumption and suggests that spontaneous GABA channel opening and increased tonic inhibition in the accumbens are critically important factors in this debilitating behavioural phenotype that is so costly to individuals and society. 


\section{Methods}

Mice. Mice were housed under standard conditions with a commercial diet (SDS, UK) and drinking water ad libitum. Using alcohol-averse background strains, 12-week-old male BALB/cAnN mice were exposed to $\mathrm{ENU}^{25}$ and crossed to WT $\mathrm{C} 3 \mathrm{H} / \mathrm{HeH}$ females. G1 progeny $(n=1,047)$ were screened in a two-bottle choice test for preference for $10 \%(v / v)$ ethanol at age 7-12 weeks. Mice showing ethanol preference ( $>2.5$ s.d. above a control non-mutagenized BALB/cAnN x C3H/HeH cohort) were backcrossed to $8-12$-week-old $\mathrm{C} 3 \mathrm{H} / \mathrm{HeH}$ females to test heritability. Our study was approved by the local ethical review panels of the MRC Mammalian Genetics Unit (MRC Harwell), the University of Dundee and the University of Sussex, and complies with the UK Animal (Scientific Procedures) Act 1986.

Phenotyping. Male and female 7-12-week-old adult mice were singly housed with free choice of water or ethanol (3 or $10 \% v / v)$ during two 10-day test periods. Consumption was determined by weighing the drinking bottles. The amount consumed was corrected for leakage and evaporation and expressed as grams ethanol consumed daily per kg body weight of the mice measured at the beginning of each period. Preference was calculated as the ratio of ethanol over total amount of liquid imbibed. Taste preference was determined similarly using 15 and $120 \mathrm{mM}$ sucrose (caloric value), $0.25 \mathrm{mM}$ and $0.4 \mathrm{mM}$ saccharin (no caloric value) and $0.05 \mathrm{mM}$ quinine. For self-administration of ethanol studies, animals ( $n=8$ group) were trained using a sucrose-fading procedure to self-administer up to $10 \% v / v$ ethanol ${ }^{19,20}$. Intoxication was scored as normal, mild ataxia or ambulatory impairment, upon removal of the animals from the operant boxes at the end of daily sessions.

Mapping of ENU Mutation. A genome scan was performed on 13 animals (2 G2, 11 G3) displaying high ethanol preference using 86 microsatellite markers distributed throughout the genome to differentiate $\mathrm{DNA}$ of $\mathrm{BALB} / \mathrm{cAnN}$ or $\mathrm{C} 3 \mathrm{H} / \mathrm{HeH}$ origin. A further 169 animals were used to identify informative recombinants. Fine mapping with additional microsatellite markers in the candidate region was undertaken to narrow the location of the mutation.

Candidate gene sequencing. Exons and the exon/intron borders of twelve can didate genes were sequenced from both directions in mutant and WT mice. Oligonucleotides were designed using Ensembl v36 predictions (http://ensembl.org) Data were analysed with BioEdit software. Primer sequences can be found in Supplementary Table S6.

Electrophysiology and analysis of brain slice preparations. Coronal slices $(300 \mu \mathrm{m})$ containing the NAc were prepared from male Gabrb1 $1^{+/ L 285 R}$ Gabrb1 $1^{+/ P 228 H}$ and WT littermates (age 2-5 months). As previously described ${ }^{34}$, slices were cut in oxygenated ice-cold maintenance solution containing $(\mathrm{mM})$ : $140 \mathrm{~K}$ gluconate, $15 \mathrm{Na}$ gluconate, $4 \mathrm{NaCl}, 10$ HEPES and 0.2 EGTA (pH 7.2; $310-320 \mathrm{mOsm})$, before storage for at least $1 \mathrm{~h}$ at room temperature $\left(20-23^{\circ} \mathrm{C}\right)$ in oxygenated, extracellular solution (ECS) containing (mM): $126 \mathrm{NaCl}, 2.95 \mathrm{KCl}, 26$ $\mathrm{NaHCO}_{3}, 1.25 \mathrm{NaH}_{2} \mathrm{PO}_{4}, 2 \mathrm{CaCl}_{2}, 10$ D-glucose and $2 \mathrm{MgCl}_{2}(\mathrm{pH} 7.4 ; 300-310$ mOsm). MSNs were identified with an Olympus BX51 microscope equipped with $\mathrm{DIC} /$ infrared optics. Whole-cell voltage-clamp recordings $(-60 \mathrm{mV})$ were performed at $35^{\circ} \mathrm{C}$, using the ECS containing $1 \mu \mathrm{M}$ strychnine, $2 \mathrm{mM}$ kynurenic acid and $0.5 \mu \mathrm{M}$ tetrodotoxin (TTX). Patch electrodes (3-4 M $\Omega$ ) were filled with (mM): $135 \mathrm{CsCl}, 10$ HEPES, 10 EGTA, $1 \mathrm{CaCl}_{2}, 2 \mathrm{MgCl}_{2}$ and $2 \mathrm{Mg}$-ATP, 5 QX-314 (pH 7.2-7.3 with $\mathrm{CsOH}, 300-308$ mOsm).

Recordings were discarded if series resistance changed by $>20 \%$. Currents were filtered at $2 \mathrm{kHz}$ (8-pole, low-pass Bessel filter) and recorded for offline analysis (DTR1205 recorder). Bicuculline methobromide, gabazine, THIP and strychnine hydrochloride were prepared as aqueous stock solutions for dilution in ECS. Picrotoxin was prepared in ECS. All drugs were obtained from Sigma-Aldrich (Poole, UK) or Tocris Bioscience (Bristol, UK). THIP and ethanol were allowed to infiltrate the slice for at least $10 \mathrm{~min}$ before data acquisition. Recordings were digitized (NIDQMX, National Instruments) and sampled at $10 \mathrm{kHz}$ before analysis (WinEDR/WinWCP). The mIPSCs were threshold-detected $(-4 \mathrm{pA}$, duration $3 \mathrm{~ms}$ ) and visually inspected. A minimum of 50-100 mIPSCs were used for analysis, including peak amplitude, rise time $(10-90 \%, \leq 1 \mathrm{~ms})$ and decay times. The decay phase of mIPSCs was best fit (98-10\% of the peak amplitude) with a biexponential $\left(y(t)=A_{\text {fast }} \mathrm{e}^{(-t / \text { fast })}+A_{\text {slow }} \mathrm{e}^{(-t / \text { tslow })}\right)$ function, where $t$ is time, $A$ is the amplitude and $\tau$ is the decay time constant. A weighted decay time constant $\left(\tau_{\mathrm{w}}\right)$ was calculated from the equation: $\tau_{\mathrm{w}}=\tau_{1} P_{1}+\tau_{2} P_{2}$, where $\tau_{1}$ and $\tau_{2}$ are decay time constants and $\mathrm{P}_{1}$ and $\mathrm{P}_{2}$ the relative proportions of the decay described by each component. The mIPSC frequency was determined in 20 -s bins for $2 \mathrm{~min}$, detected by the rate of rise $\left(30-50 \mathrm{pA} \mathrm{ms}^{-1}\right)$, excluding spurious noise.

The mean current and associated RMS were calculated over $102.4 \mathrm{~ms}$ epochs for $1 \mathrm{~min}$, using a $10-\mathrm{kHz}$ sampling rate. Epochs containing mIPSCs or unstable baseline were excluded. To ensure changes in the holding current reflected a drug effect, two 1-min control holding current periods ( $\mathrm{C} 1$ and $\mathrm{C} 2$ ) were sampled and a 1-min section after drug equilibration (D). The mean holding current for $\mathrm{C} 1$ and $\mathrm{C} 2$ were pooled and the s.d. calculated. The drug effect was accepted if the absolute change in the holding current $(\mathrm{D}-\mathrm{C} 2)$ was greater than twice the standard deviation of the controls $(\mathrm{C} 1, \mathrm{C} 2)$. For electrophysiological analysis of brain slice recordings all data reported represent the mean \pm s.e.m. of observations derived from a minimum of three animals and each determination is derived from an individual slice.

Site-directed mutagenesis. All point mutations in the $\mathrm{GABA}_{\mathrm{A}} \mathrm{R} \beta$ subunit were introduced using Quikchange (Stratagene). Sequences of the full coding region of mutated murine cDNAs were determined by automated fluorescent sequencing. Plasmid DNAs for transfection were purified using the Hi-Speed Plasmid Midi Kit (Qiagen).

Cell culture and electrophysiology. HEK293 cells (ATCC, Middlesex, UK) were cultured in Dulbecco's modified Eagle's medium with $10 \% v / v$ fetal calf serum, $2 \mathrm{mM}$ glutamine, 100 units per $\mathrm{ml}$ penicillin $\mathrm{G}$ and $100 \mathrm{mg} \mathrm{ml}^{-1}$ streptomycin at $37^{\circ} \mathrm{C}$ in $95 \%$ air $/ 5 \% \mathrm{CO}_{2}$. Cells were transiently transfected by calcium phosphate co-precipitation using $1 \mu \mathrm{g}$ of each plasmid DNA encoding for $\alpha 2, \alpha 4, \beta 1, \delta$ or $\gamma 2$ and $0.5 \mu \mathrm{g}$ Enhanced Green Fluorescent Protein (GFP; Clontech) and used for electrophysiology after $20 \mathrm{~h}$.

Whole-cell currents were recorded at room temperature $\left(20-22^{\circ} \mathrm{C}\right)$ from single HEK293 cells voltage clamped at $-40 \mathrm{mV}$, using an Axopatch 200B amplifier (Molecular Devices, USA). Patch electrodes (3-5 M $)$ ) contained (mM): $144 \mathrm{KCl}$, $2 \mathrm{MgCl}_{2}, 1 \mathrm{CaCl}_{2}, 10$ HEPES, 11 EGTA and 2 adenosine triphosphate (pH 7.2). Cells were superfused with Krebs solution containing (mM): $140 \mathrm{NaCl}, 4.7 \mathrm{KCl}, 1.2$ $\mathrm{MgCl}_{2}, 2.5 \mathrm{CaCl}_{2}, 10$ HEPES and 11 glucose $(\mathrm{pH} 7.4)$. Recordings were filtered at $5 \mathrm{kHz}$ (6-pole Bessel, $36 \mathrm{~dB}$ per octave). Drugs and Krebs solution were applied using a modified U-tube. GABA, bicuculline, picrotoxin and ethanol were dissolved directly into Krebs solution (adjusted to $\mathrm{pH}$ 7.4). Allopregnanolone and diazepam were diluted in Krebs from a $10 \mathrm{mM}$ stock in DMSO. For whole-cell studies of ethanol potentiation, the GABA current evoked by a low GABA concentration $\left(\mathrm{EC}_{10}\right)$ was initially determined, then $30-200 \mathrm{mM}$ ethanol was applied for $30-60 \mathrm{~s}$ prior to the co-application of $\mathrm{EC}_{10} \mathrm{GABA}$ and ethanol. Allopregnanolone potentiation was determined by co-application with $\mathrm{EC}_{10} \mathrm{GABA}$ and the neurosteroid. Dose-response relationship data were fitted with a non-linear least squares fitting routine using Origin 6.1 (Microcal). Data points represent the mean \pm s.e.m. of at least three experiments. The relative proportion of spontaneous $\mathrm{GABA}_{\mathrm{A}}$ receptor activation was ascertained by dividing the amplitude of currents induced by saturating concentrations of PTX $\left(I_{\mathrm{PTX}}\right)$ by the summed current amplitudes induced by saturating concentrations of PTX and GABA $\left(I_{\mathrm{GABA}}+\right.$ $\left.I_{\mathrm{PTX}}\right)$. Single-channel currents were recorded at room temperature from excised outside-out membrane patches maintained at $-70 \mathrm{mV}$ (sampling rate $50 \mathrm{kHz}$; low pass-filtered at $10 \mathrm{kHz}$ during recording, and at $2-5 \mathrm{kHz}$ during analysis). Patches showing multiple simultaneous channel openings (channel stacking) exceeding $2 \%$ of all detected openings were discarded.

Single-channel data were analysed using WinEDR (v.3.3.8; Strathclyde electrophysiology software, J Dempster) and QuB (2.0.0.13, Buffalo, NY). Amplitude histograms were created by fitting Gaussian components to the amplitude distributions using a non-linear least-squares routine. Open probabilities (Po) were defined as the ratio between the Gaussian areas of open and shut time components. Individual open and shut time durations were idealized using either WinEDR's $50 \%$ threshold detection method or by QuB's segmental k-means (SKM) fitting routine. Open and shut dwell-time histograms were fitted with a mixture of exponentials using a Levenberg-Marquardt non-linear least-squares method from which the areas representing the individual exponential components and their relative time constants were obtained. Mean dwell-time durations were calculated from the individual open and shut times weighted by their areas $33,46,47$

Confocal microscopy and immunocytochemistry. $\mathrm{GABA}_{\mathrm{A}} \mathrm{R}$ receptor $\alpha 2, \beta 1^{\text {myc }}$ or $\beta 1^{\text {myc,L285R }}$ or $\beta 1^{\text {myc,P2228H }}$, and $\gamma 2 S$ or $\gamma 2 \mathrm{~L}$ subunits were expressed with eGFP in HEK293 cells and incubated at room temperature with 9E10 antibody (to the extracellular myc epitope; Santa Cruz Biotechnology) followed by TRITC- or Cy5conjugated secondary antibody. The myc epitope in the $\beta 1$ subunit is electrophysiologically silent ${ }^{48}$. Transfected HEK293 cells were fixed in phosphate-buffered saline (PBS) containing $4 \%$ paraformaldehyde for $15 \mathrm{~min}$ before being quenched with $50 \mathrm{mM} \mathrm{NH}_{4} \mathrm{Cl}$ in PBS for $10 \mathrm{~min}$. After washing in PBS, cells were incubated for $45 \mathrm{~min}$ at room temperature with 9E10 antibody. Cells were washed in PBS containing $10 \% v / v$ fetal calf serum (FCS) and $0.4 \% w / v$ bovine serum albumin (BSA) before incubation for $45 \mathrm{~min}$ with a TRITC- or Cy5-conjugated secondary antibody. Cells were washed and then mounted in glycerol before imaging using a Zeiss Axiophot confocal microscope (LSM510 Meta). The detector gain, and amplifier offset and gain were set at the same levels for all FITC, TRITC and Cy5 images of WT and mutant receptors to compare expression intensities. The scanning slice depth was set to $2.1 \mu \mathrm{m}$.

Statistical analysis. Analyses were performed using SPSS v14 and SigmaStat software (SPSS, USA). Data are presented as mean \pm s.e.m. or $95 \%$ confidence intervals unless otherwise stated. Student's $t$-tests were used for two group comparisons (paired or unpaired as appropriate). Multifactorial linear model analysis was used to investigate the effect of genotype on alcohol preference, correcting for generation, gender and weight. Two-way ANOVA, with the between-subject facto 
'genotype' and within-subject factor 'session', was used to evaluate potential gen otype and reinforcer type effect and any interactions, and lever pressing in extinction. Categorized indices were compared using a Fisher's exact test. The nonparametric Kolmogorov-Smirnoff test was used to compare cumulative probability distributions of IPSC parameters. Statistical significance was routinely set at $P<0.05$ and at $P<0.01$ for the Kolmogorov-Smirnoff test.

\section{References}

1. Whiting, P. J., McKernan, R. M. \& Wafford, K. A. Structure and pharmacology of vertebrate GABAA receptor subtypes. Int. Rev. Neurobiol. 38, 95-138 (1995).

2. Edenberg, H. J. et al. Variations in GABRA2, encoding the alpha 2 subunit of the GABA(A) receptor, are associated with alcohol dependence and with brain oscillations. Am. J. Hum. Genet. 74, 705-714 (2004).

3. Enoch, M. A. The role of GABA(A) receptors in the development of alcoholism. Pharmacol. Biochem. Behav. 90, 95-104 (2008).

4. Parsian, A. \& Zhang, Z. H. Human chromosomes 11 p15 and 4 p12 and alcohol dependence: possible association with the GABRB1 gene. Am. J. Med. Genet. 88, 533-538 (1999).

5. Porjesz, B. et al. Linkage disequilibrium between the beta frequency of the human EEG and a GABAA receptor gene locus. Proc. Natl Acad. Sci. USA 99, 3729-3733 (2002).

6. Reck, B. H., Mukhopadhyay, N., Tsai, H. J. \& Weeks, D. E. Analysis of alcohol dependence phenotype in the COGA families using covariates to detect linkage. BMC Genet. 6(Suppl 1): S143 (2005).

7. Agrawal, A. et al. Association of GABRA2 with drug dependence in the collaborative study of the genetics of alcoholism sample. Behav. Genet. 36, 640650 (2006).

8. Bauer, L. O. et al. Variation in GABRA2 predicts drinking behavior in project MATCH subjects. Alcohol Clin. Exp. Res. 31, 1780-1787 (2007).

9. Covault, J., Gelernter, J., Hesselbrock, V., Nellissery, M. \& Kranzler, H. R. Allelic and haplotypic association of GABRA2 with alcohol dependence. Am. J. Med. Genet. B. Neuropsychiatr. Genet. 129B, 104-109 (2004).

10. Dick, D. M. et al. The role of GABRA2 in risk for conduct disorder and alcohol and drug dependence across developmental stages. Behav. Genet. 36, 577-590 (2006).

11. Olsen, R. W. \& Sieghart, W. International Union of Pharmacology. LXX. Subtypes of gamma-aminobutyric acid(A) receptors: classification on the basis of subunit composition, pharmacology, and function. Update. Pharmacol. Rev. 60, 243-260 (2008).

12. Pirker, S., Schwarzer, C., Wieselthaler, A., Sieghart, W. \& Sperk, G. GABA(A) receptors: immunocytochemical distribution of 13 subunits in the adult rat brain. Neuroscience 101, 815-850 (2000).

13. Rudolph, U. \& Mohler, H. Analysis of GABAA receptor function and dissection of the pharmacology of benzodiazepines and general anesthetics through mouse genetics. Annu. Rev. Pharmacol. Toxicol. 44, 475-498 (2004).

14. Boehm, 2nd S. L. et al. gamma-Aminobutyric acid A receptor subunit mutant mice: new perspectives on alcohol actions. Biochem. Pharmacol. 68, 1581-1602 (2004).

15. Engin, E., Liu, J. \& Rudolph, U. alpha2-containing GABA(A) receptors: a target for the development of novel treatment strategies for CNS disorders. Pharmacol. Ther. 136, 142-152 (2012).

16. Nie, H., Rewal, M., Gill, T. M., Ron, D. \& Janak, P. H. Extrasynaptic deltacontaining GABAA receptors in the nucleus accumbens dorsomedial shell contribute to alcohol intake. Proc. Natl Acad. Sci. USA 108, 4459-4464 (2011).

17. Rewal, M. et al. Alpha4-containing GABAA receptors in the nucleus accumbens mediate moderate intake of alcohol. J. Neurosci. 29, 543-549 (2009).

18. Mihalek, R. M. et al. GABA(A)-receptor delta subunit knockout mice have multiple defects in behavioral responses to ethanol. Alcohol Clin. Exp. Res. 25, 1708-1718 (2001)

19. Dixon, C. I., Walker, S. E., King, S. L. \& Stephens, D. N. Deletion of the gabra2 gene results in hypersensitivity to the acute effects of ethanol but does not alter ethanol self administration. PLoS One 7, e47135 (2012).

20. Stephens, D. N., Pistovcakova, J., Worthing, L., Atack, J. R. \& Dawson, G. R. Role of GABAA alpha5-containing receptors in ethanol reward: the effects of targeted gene deletion, and a selective inverse agonist. Eur. J. Pharmacol. 526, 240-250 (2005).

21. Wallner, M., Hanchar, H. J. \& Olsen, R. W. Ethanol enhances alpha 4 beta 3 delta and alpha 6 beta 3 delta gamma-aminobutyric acid type A receptors at low concentrations known to affect humans. Proc. Natl Acad. Sci. USA 100, 15218-15223 (2003).

22. Borghese, C. M. et al. The delta subunit of gamma-aminobutyric acid type A receptors does not confer sensitivity to low concentrations of ethanol. $J$. Pharmacol. Exp. Ther. 316, 1360-1368 (2006).

23. Santhakumar, V., Wallner, M. \& Otis, T. S. Ethanol acts directly on extrasynaptic subtypes of GABAA receptors to increase tonic inhibition. Alcohol 41, 211-221 (2007).
24. Baur, R., Kaur, K. H. \& Sigel, E. Structure of alpha6 beta3 delta GABA(A) receptors and their lack of ethanol sensitivity. J. Neurochem. 111, 1172-1181 (2009).

25. Nolan, P. M. et al. A systematic, genome-wide, phenotype-driven mutagenesis programme for gene function studies in the mouse. Nat. Genet. 25, 440-443 (2000).

26. Justice, M. J., Noveroske, J. K., Weber, J. S., Zheng, B. \& Bradley, A. Mouse ENU mutagenesis. Hum. Mol. Genet. 8, 1955-1963 (1999).

27. Coghill, E. L. et al. A gene-driven approach to the identification of ENU mutants in the mouse. Nat. Genet. 30, 255-256 (2002).

28. Maguire, E. P. et al. Extrasynaptic $\alpha 4 \beta \delta$ GABAARs mediate a tonic conductance in nucleus accumbens medium spiny neurons. Society for Neuroscience: Neuroscience 2012. p. 669.619/CC618 (2012).

29. McCartney, M. R., Deeb, T. Z., Henderson, T. N. \& Hales, T. G. Tonically active GABAA receptors in hippocampal pyramidal neurons exhibit constitutive GABA-independent gating. Mol. Pharmacol. 71, 539-548 (2007).

30. Luddens, H. \& Korpi, E. R. Biological function of GABAA/benzodiazepine receptor heterogeneity. J. Psychiatr. Res. 29, 77-94 (1995).

31. Ueno, S., Bracamontes, J., Zorumski, C., Weiss, D. S. \& Steinbach, J. H. Bicuculline and gabazine are allosteric inhibitors of channel opening of the GABAA receptor. J. Neurosci. 17, 625-634 (1997).

32. Bai, D. et al. Distinct functional and pharmacological properties of tonic and quantal inhibitory postsynaptic currents mediated by gamma-aminobutyric acid(A) receptors in hippocampal neurons. Mol. Pharmacol. 59, 814-824 (2001).

33. Mortensen, M. et al. Activation of single heteromeric GABA(A) receptor ion channels by full and partial agonists. J. Physiol. 557(Pt 2): 389-413 (2004).

34. Dixon, C. I. et al. Cocaine effects on mouse incentive-learning and human addiction are linked to alpha2 subunit-containing GABAA receptors. Proc. Natl Acad. Sci. USA 107, 2289-2294 (2010).

35. Kumar, S., Fleming, R. L. \& Morrow, A. L. Ethanol regulation of gammaaminobutyric acid A receptors: genomic and nongenomic mechanisms. Pharmacol. Ther. 101, 211-226 (2004).

36. Sundstrom-Poromaa, I. et al. Hormonally regulated alpha(4)beta(2)delta GABA(A) receptors are a target for alcohol. Nat. Neurosci. 5, 721-722 (2002).

37. Blomeley, C. P., Cains, S., Smith, R. \& Bracci, E. Ethanol affects striatal interneurons directly and projection neurons through a reduction in cholinergic tone. Neuropsychopharmacology 36, 1033-1046 (2011).

38. Keays, D. A., Clark, T. G. \& Flint, J. Estimating the number of coding mutation in genotypic- and phenotypic-driven N-ethyl-N-nitrosourea (ENU) screens. Mamm. Genome 17, 230-238 (2006).

39. Quwailid, M. M. et al. A gene-driven ENU-based approach to generating an allelic series in any gene. Mamm. Genome 15, 585-591 (2004).

40. Sun, F., Cheng, R., Flanders, W. D., Yang, Q. \& Khoury, M. J. Whole genome association studies for genes affecting alcohol dependence. Genet. Epidemiol. 17(Suppl 1): S337-S342 (1999).

41. Song, J. et al. Association of GABA(A) receptors and alcohol dependence and the effects of genetic imprinting. Am. J. Med. Genet. B Neuropsychiatr. Genet. 117B, 39-45 (2003).

42. Edenberg, H. J. et al. Description of the data from the Collaborative Study on the Genetics of Alcoholism (COGA) and single-nucleotide polymorphism genotyping for Genetic Analysis Workshop 14. BMC Genet. 6(Suppl 1): S2 (2005).

43. Botta, P. et al. Modulation of GABAA receptors in cerebellar granule neurons by ethanol: a review of genetic and electrophysiological studies. Alcohol 41, 187-199 (2007).

44. Yamashita, M., Marszalec, W., Yeh, J. Z. \& Narahashi, T. Effects of ethanol on tonic GABA currents in cerebellar granule cells and mammalian cells recombinantly expressing GABA(A) receptors. J. Pharmacol. Exp. Ther. 319, 431-438 (2006).

45. Kaur, K. H., Baur, R. \& Sigel, E. Unanticipated structural and functional properties of delta-subunit-containing GABAA receptors. J. Biol. Chem. 284, 7889-7896 (2009).

46. Mortensen, M., Ebert, B., Wafford, K. \& Smart, T. G. Distinct activities of GABA agonists at synaptic- and extrasynaptic-type GABAA receptors. J. Physiol. 588(Pt 8): 1251-1268 (2010).

47. Mortensen, M. \& Smart, T. G. Single-channel recording of ligand-gated ion channels. Nat. Protoc. 2, 2826-2841 (2007).

48. Connolly, C. N., Krishek, B. J., McDonald, B. J., Smart, T. G. \& Moss, S. J. Assembly and cell surface expression of heteromeric and homomeric gammaaminobutyric acid type A receptors. J. Biol. Chem. 271, 89-96 (1996).

\section{Acknowledgements}

This work was supported by MRC (UK), Wellcome Trust and ERAB awards to H.C.T. Q.M.A., S.K., T.G.S., D.N.S., D.B. and J.J.L. (all members of the MRC Addiction Research Cluster and the MRC/IMPC UK GoLD 'Genetics of Liver Disease' consortium). We thank Z. Tymowska-Lalanne, A. Kopp-Schneider, J. Saini, M. Kajihara, G. Lydall, E. Prescott and L. Jones for advice and/or technical support, and A. Parlow for 
radioimmunoassay reagents, performed by D. Carmignac (NIMR) and I. Huhtaniemi's laboratory.

\section{Author contributions}

H.C.T., S.D.M.B. and E.M.C.F. conceived the research. The ENU screen was conducted by A.M., S.K., Q.M.A. and H.C.T. In vivo phenotyping and preference testing was conducted and overseen by S.K. and Q.M.A. Endocrine studies were performed by I.R. In vitro electrophysiology studies were conducted by A.M.H., P.T., M.M., R.B. and T.G.S. In vivo operant conditioning, ethanol kinetics and ataxia studies were performed by S.E.W., C.I.D. and D.N.S. Ex vivo brain slice electrophysiology studies were conducted by E.P.M., D.B. and J.J.L. Additional phenotyping, data/sample acquisition and scientific support was performed by Y.-T.H., A.H., M.A.U., J.D.B., M.Y.M., S.M., K.R., H.M.D.G., A.M. and I.G. Data analysis and interpretation was performed by Q.M.A., S.K., T.G.S., D.N.S., E.P.M., D.B., J.J.L. and H.C.T. The manuscript was written and revised by
Q.M.A., S.K., D.B., J.J.L., D.N.S., T.G.S. and HCT. All authors reviewed and approved the submitted manuscript. D.N.S., D.B., S.B., J.J.L., T.G.S. and H.C.T. are joint senior authors.

\section{Additional information}

Supplementary Information accompanies this paper at http://www.nature.com/ naturecommunications

Competing financial interests: The authors declare no competing financial interests.

Reprints and permission information is available online at http://npg.nature.com/ reprintsandpermissions/

How to cite this article: Anstee, Q. M. et al. Mutations in the Gabrb1 gene promote alcohol consumption through increased tonic inhibition. Nat. Commun. 4:2816 doi: $10.1038 /$ ncomms3816 (2013). 